\title{
Geologia
}

\section{Estruturação "em rosário" dos depósitos de quartzo hidrotermal do Morro do Juá (Gouveia, MG)}

\author{
Mario Luiz de Sá C. Chaves \\ Professor do IGC/UFMG e Pesquisador do MHN/UFMG, Belo Horizonte-MG \\ E-mail:mchaves@igc.ufmg.br \\ Joachim Karfunkel \\ Professor do IGC/UFMG e Pesquisador do MHN/UFMG, Belo Horizonte-MG \\ E-mail: jokarfun@igc.ufmg.br \\ Miguel Tupinambá \\ Professor da Faculdade de Geologia, UERJ, Rio de Janeiro-RJ \\ E-mail: tupi@uerj.br
}

\section{Resumo}

Veios de quartzo hidrotermal ocorrem na área a oeste do Morro do Juá (Gouveia-MG), definindo uma forma típica "em rosário", controlada pela estratigrafia e estruturas da área. Os veios, normalmente zonados, ocorrem em quartzitos grossos da Formação São João da Chapada (Supergrupo Espinhaço), que sobrepõem xistos do Supergrupo Rio Paraúna e são capeados por metabasitos. Apresentam atitudes preferenciais com pólos centralizados em $\mathrm{N} 05^{\circ} \mathrm{E} / 73^{\circ} \mathrm{NW}$ e $\mathrm{N} 18^{\circ} \mathrm{E} / 74^{\circ} \mathrm{SE}$, os quais indicam, respectivamente, suas prováveis direções de condução e alojamento. A gênese desses veios condiciona-se à formação de zonas de cisalhamento durante o Ciclo Brasiliano.

Palavras-chave: quartzo, depósitos minerais, geologia estrutural.

\begin{abstract}
Hydrothermal quartz veins occur west of the Juá Hill (Gouveia-MG). They form a typical "rosario"shape structure, which is controlled by the stratigraphy and tectonic setting of the area. The veins are usually zoned and have been observed emplaced in quartzites of the São João da Chapada Formation (Espinhaço Supergroup). The latter covers mica-schists of the Rio Paraúna Supergroup and is overlain by a sill of metabasic rock. Main attitude of the quartz veins (around NO5 ${ }^{\circ} \mathrm{E} / 73^{\circ} \mathrm{NW}$ e $\mathrm{N} 18^{\circ} \mathrm{E} / 74^{\circ} \mathrm{SE}$ ) indicate possible conduction direction and emplacement. Genetically these veins are related to the formation of shear zones during the Brasiliano Cycle.
\end{abstract}

Keywords: quartz, mineral deposits, structural geology. 


\section{Introdução}

$\mathrm{Na}$ Serra do Espinhaço Meridional, uma infinidade de veios de quartzo hidrotermal, gerados pela orogenia e metamorfismo do Brasiliano (Neoproterozóico), se associam principalmente a litologias metapelíticas do Supergrupo Espinhaço (Mesoproterozóico), ou às faixas de milonitização das rochas granitóides do Complexo Basal (Arqueano). Os veios, de elevada pureza, em geral são minerados quando possuem espessura média superior a $1 \mathrm{~m}$, sendo o material leitoso aproveitado para fundição (redução da sílica em Si-metálico) e o material cristalizado, para fins ópticos e/ou gemológicos.

Diversos estudos visando à tipologia e aos aspectos mineralógicos desses veios permitiram a obtenção de um razoável acervo de dados sobre suas condições genéticas (Carvalho, 1982, Dossin et al., 1990, Chaves et al., 1997, 1999, Cruz, 2000, Favacho-Silva, 2000). Na presente ocasião, tais veios foram detalhados nas proximidades do Morro do Juá, ao norte de Gouveia, sendo que a interpretação do controle geral dos corpos assim como os mecanismos de seus emplacements constituem-se nos principais objetivos desse trabalho.

\section{Geologia da área do Morro do Juá}

Estudos preliminares sobre a região, enfocando, na maior parte, seus aspectos litoestratigráficos, são devidos a Fogaça e Schöll (1984). Levantamentos recentes realizados pelos autores incluíram também os diversos aspectos estratigráficos e estruturais que influenciaram na formação dos depósitos de quartzo da área, demonstrando a existência de uma estrutura braquissinclinal de eixos norte-sul e leste-oeste, onde, em seu flanco oeste, uma zona de cisalhamento desenvolve-se no contato por empurrão do Supergrupo Espinhaço com rochas do embasamento arqueano (Figura 1).

\section{Complexo Pré-Espinhaço - Rochas graníticas}

Rochas do Embasamento Cristalino afloram na porção sudoeste da área em foco, constituindo regionalmente o fechamento ao norte da estrutura conhecida como "Anticlinal de Gouveia" (Pflug, 1965). Nessa área, o relevo é bastante aplainado, com poucos afloramentos formados de matacões isolados de rochas graníticas, em termos petrográficos compostas de quartzo, feldspato potássico (caolinizado), plagioclásio, biotita e sericita, sendo que os K-feldspatos mostram formas sigmoidais, sugerindo que a rocha tenha sido milonitizada. Segundo Hoffmann (1980), tais gra- nitos apresentam aspectos mineralógicos que os permitem considerar como do "tipo-s".

\section{Supergrupo Rio Paraúna}

Aflorando a oeste e leste do Morro do Juá, rochas xistosas normalmente atribuídas ao Supergrupo Rio Paraúna (Fogaça \& Schöll, 1984) sobrepõem-se aos granitóides do Complexo Basal, apresentando espessura aproximada de $100 \mathrm{~m}$. De modo típico, na parte oeste da área, tais litologias compõem um alinhamento estrutural de direção $\mathrm{N} 20^{\circ} \mathrm{W}$ evidente nas fotografias aéreas, caracterizado em campo por uma encosta
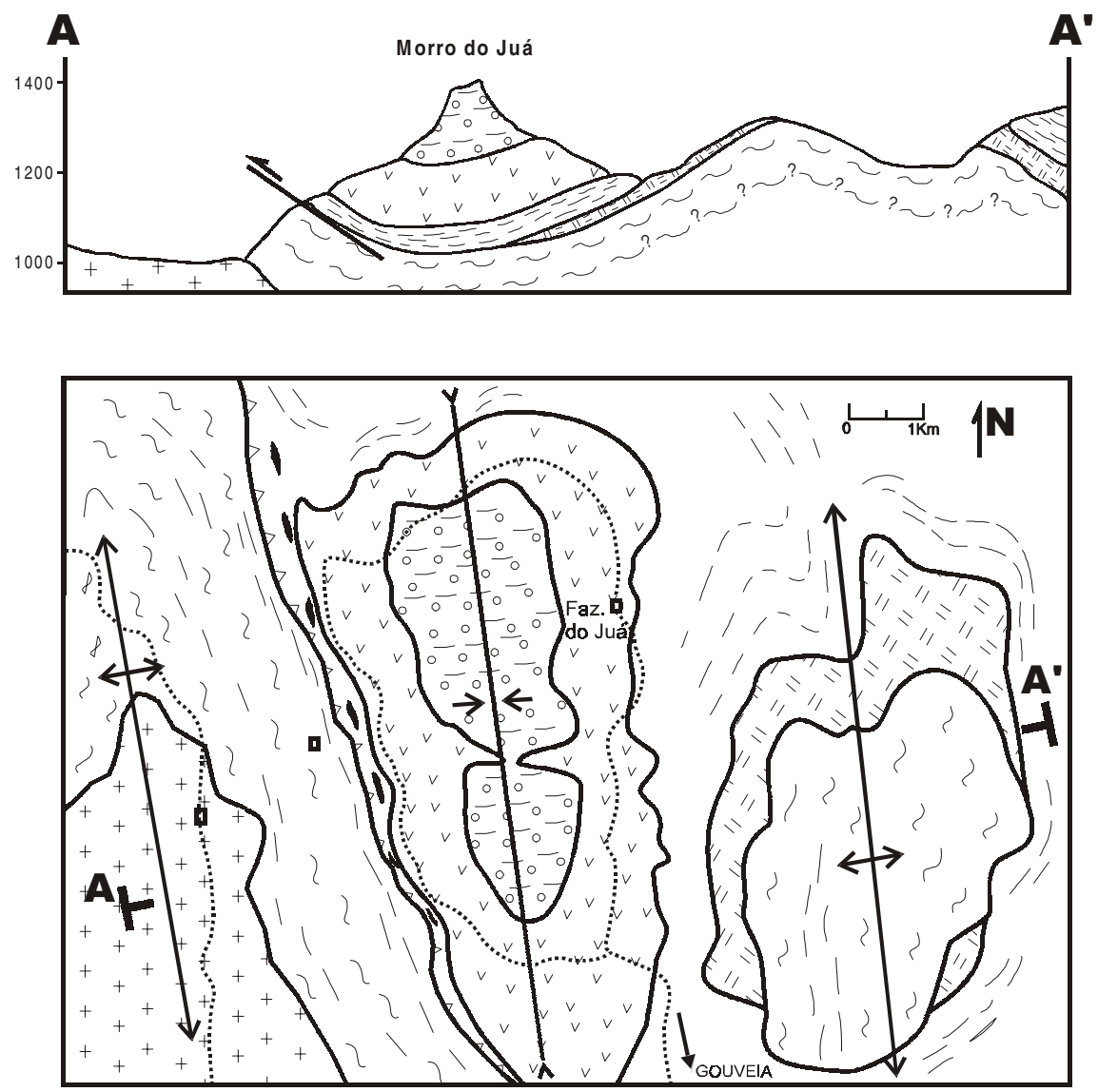

LEGENDA

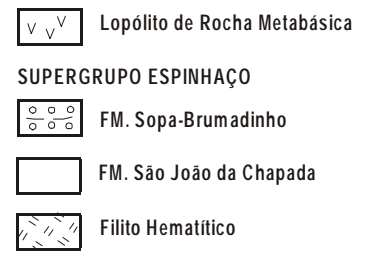

COMPLEXO PRÉ-ESPINHAÇO

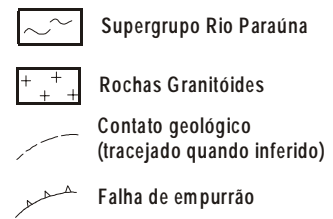

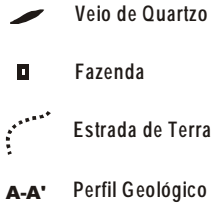

Figura 1 - Mapa e perfil geológicos da área do Morro do Juá (Gouveia, MG). 
abrupta com desnível de 50-70 m, onde podem ser perfilados os diversos litotipos constituintes da unidade. Na base da seqüência (10-20 m), ocorrem clorita xistos finos, esverdeados, com cristais milimétricos de magnetita euédrica, que gradam em direção ao topo para tipos mais grossos, formando localmente muscovita xistos e muscovita-quartzocianita xistos, que definem uma zona de deformação mais acentuada.

\section{Supergrupo Espinhaço - Filito hematítico}

Essa rocha peculiar ocorre exclusivamente a leste da área, capeando diretamente os litotipos xistosos do Supergrupo Rio Paraúna, com afloramentos isolados mas que fornecem uma cobertura coluvionar generalizada com seixos e blocos do material. A espessura total da camada é inferior a $15 \mathrm{~m}$, adelgaçando-se para oeste a julgar pelo seu completo desaparecimento naquele setor do Morro do Juá. A rocha é constituída exclusivamente de sericita $(65-80 \%)$ e hematita (20-35\%), com nódulos milimétricos de turmalina preta e hematita. Desde longa data, tais rochas são consideradas como magmáticas intrusivas, associando-se, segundo os modelamentos tectônicos regionais atualmente aceitos, às fases iniciais de abertura do rifte do Espinhaço, sendo datadas em 1,75 Ga (Dossin, 1994).

\section{Formação São João da Chapada}

Essa unidade, integrante da porção basal do Supergrupo Espinhaço (Grupo Diamantina), aparece circundando o Morro do Juá, definindo a grande estrutura braquissinclinal que caracteriza tal feição topográfica. A seqüência, de 100$120 \mathrm{~m}$ de espessura, é bastante heterogênea, constituída na base por quartzitos médios a grossos, muitas vezes microconglomeráticos e com abundantes estratificações cruzadas acanaladas, que gradam em direção ao topo para quartzitos finos, mais homogêneos, com estratificações plano-paralelas ricas em marcas de ondas. Nessa última seção, ob- servam-se, ainda, localmente, metarritimitos de areia fina e silte, em que a presença de óxidos de ferro nas porções sílticas confere à rocha uma aparência de formação ferrífera bandada. A oeste da serra, a porção basal da unidade é truncada bruscamente pela zona de cisalhamento, restringindo sua espessura à faixa de 20-30 m, onde se alojaram numerosos e quase contínuos veios de quartzo, que serão detalhados nos capítulos subseqüentes.

\section{Formação Sopa- Brumadinho}

Essa unidade aparece na porção central da área, constituindo o núcleo da estrutura braquissinclinal do Morro do Juá, com espessura (mínima) aproximada de $150 \mathrm{~m}$. Ela é formada basicamente de quartzitos finos a médios, bastante micáceos, que conferem à rocha uma coloração rósea de alteração. Em apenas um local (porção sudeste da estrutura), observou-se um paraconglomerado monomítico e pouco espesso $(<1 \mathrm{~m})$, com seixos centimétricos de quartzo e quartzito. Estratificações cruzadas, de médio porte e baixo ângulo são muito comuns. Nas partes mais altas da serra, porém, separada por um patamar de desnível marcante nas fotografias aéreas, aparece uma seqüência de quartzitos finos e bem selecionados, com estratos cruzados de alto ângulo e grande porte, indicando prováveis depósitos eólicos, que talvez possam ser correlacionados à Formação Galho do Miguel, que é estratigraficamente superior.

\section{Rochas metabásicas}

Ocorrendo em volta do Morro do Juá, um corpo extenso e homogêneo de rocha metabásica com cerca de $120 \mathrm{~m}$ de espessura aloja-se em concordância na zona de contato entre as formações São João da Chapada e Sopa - Brumadinho, podendo ser classificado em termos morfológicos como um lopólito. Análises petrográficas mostraram que na área tal rocha é constituída de actinolita (>60\%), plagioclásio, leucoxênio e rutilo, sendo classificada como um anfibo- lito. A oeste da serra, essa litologia serviu como capeadora dos fluidos ascendentes, que formaram a estrutura "em rosário" dos veios de quartzo estudados.

\section{Descrição e controle da mineralização de quartzo}

Os veios de quartzo apresentam espessuras variáveis entre alguns milímetros até $3 \mathrm{~m}$, estando espalhados longitudinalmente por $2,5 \mathrm{~km}$ segundo direção geral $\mathrm{N} 20^{\circ} \mathrm{W}$. A conformação geral desses veios na área permite determinar uma típica morfologia "em rosário" para o depósito como um todo, de acordo com a conceituação de Routhier (1970), isto é, grandes massas isoladas ou ligadas entre si por delgada porção do mesmo material (as "contas" do rosário) mineralizado segundo uma direção definida. Cada uma dessas seções possui entre 10 e $30 \mathrm{~m}$ de comprimento (Figura 2). Em escala de afloramento, tal estrutura também é conhecida como pinch-and-swell, embora, nesse caso, uma conotação genética esteja envolvida (Ramberg, 1955).

Quando a espessura dos veios é maior que $2 \mathrm{~m}$, um zoneamento pode ser localmente observado, de modo semelhante ao já descrito por Carvalho (1982) na região de Pedro Pereira, ao sul de Gouveia:

- Zona 1 (externa) - quartzito grosso encaixante, bastante fraturado e parcialmente recristalizado.

- Zona 2 (de borda) - podendo estar ausente, em geral com menos de $30 \mathrm{~cm}$ de espessura, apresenta fragmentos brechóides de quartzito cimentados por quartzo leitoso bastante fraturado e quebradiço.

- Zona 3 (maciça) - de quartzo brancoleitoso, maciço e pouco fraturado, constituindo o principal material lavrado para obtenção do Si-metálico por fundição.

- Zona 4 (de núcleo) - com frequiência ausente, caracterizada por quartzo relativamente menos leitoso e algo cristalizado, onde podem aparecer cavi- 
dades irregulares preenchidas por drusas de quartzo hialino, fumé ou com inclusões de clorita. Os cristais bem formados podem atingir no máximo alguns centímetros de comprimento, sendo utilizados na indústria gemológica ou como material para coleção.

Tais veios são praticamente monominerálicos, notando-se, por vezes, raros "filmes" contendo hematita e/ou óxido de manganês. Ocorrem segundo duas direções evidentes, conforme pode ser observado nos estereogramas apresentados na Figura 3, definindo planos aproximadamente coaxiais com pólos máximos em N5 ${ }^{\circ} \mathrm{E} / 73^{\circ} \mathrm{NW}$ e $\mathrm{N} 18^{\circ} \mathrm{E} / 74^{\circ} \mathrm{SE}$. A zona 4 parece ser preferencial nos veios do primeiro grupo, concordantes com a estratificação original da rocha (Figura 4).

A mineralização de quartzo do Morro do Juá mostra um notável controle estratigráfico e estrutural. Assim, deve-se ressaltar que os veios ocorrem exclusivamente alojados nos quartzitos grossos da Formação São João da Chapada. Entretanto essa condição estratigráfica por si só tem pouca importância, tendo em vista que a mesma formação ocupa extensas área a leste da serra (Figura 1), onde a ocorrência de veios de quartzo é desprezível.

Dessa maneira, o condicionamento da Formação São João da Chapada como uma camada "reservatório" a oeste da serra é o resultado de sua associação com uma camada "alimentadora" de flui- dos, basal (xistos e filonitos do Supergrupo Rio Paraúna), e uma camada "seladora" no topo (o lopólito de rocha metabásica) (Figura 5). Tal relacionamento é bastante conhecido na geologia de hidrocarbonetos, onde condições semelhantes são necessárias para a existência de horizontes mineralizados em petróleo e/ou gás.

\section{Discussões quanto à gênese dos depósitos}

Os dados apresentados demonstram os diversos fatores que condicionaram a formação dos veios com mor-

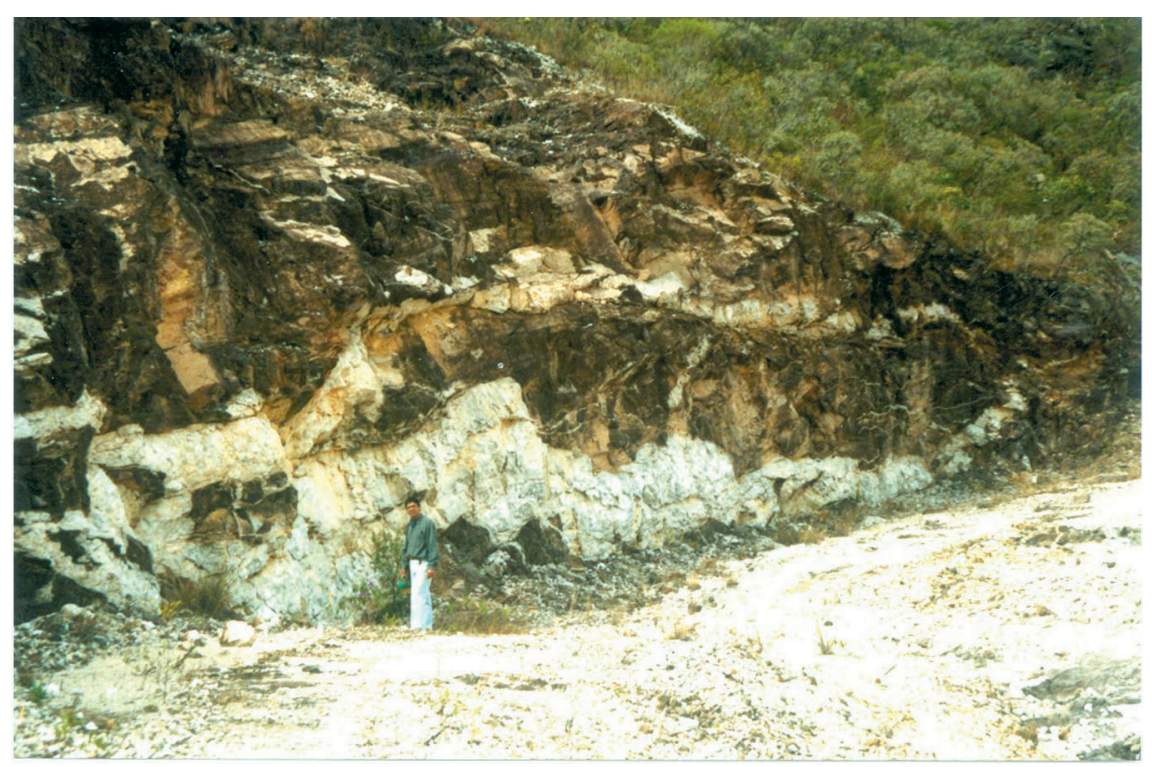

Figura 2 - Visão geral de uma das seções (ou "contas") do rosário de quartzo, encaixado no quartzito da Formação da São João da Chapada, em lavra desativada a noroeste da serra do Juá.
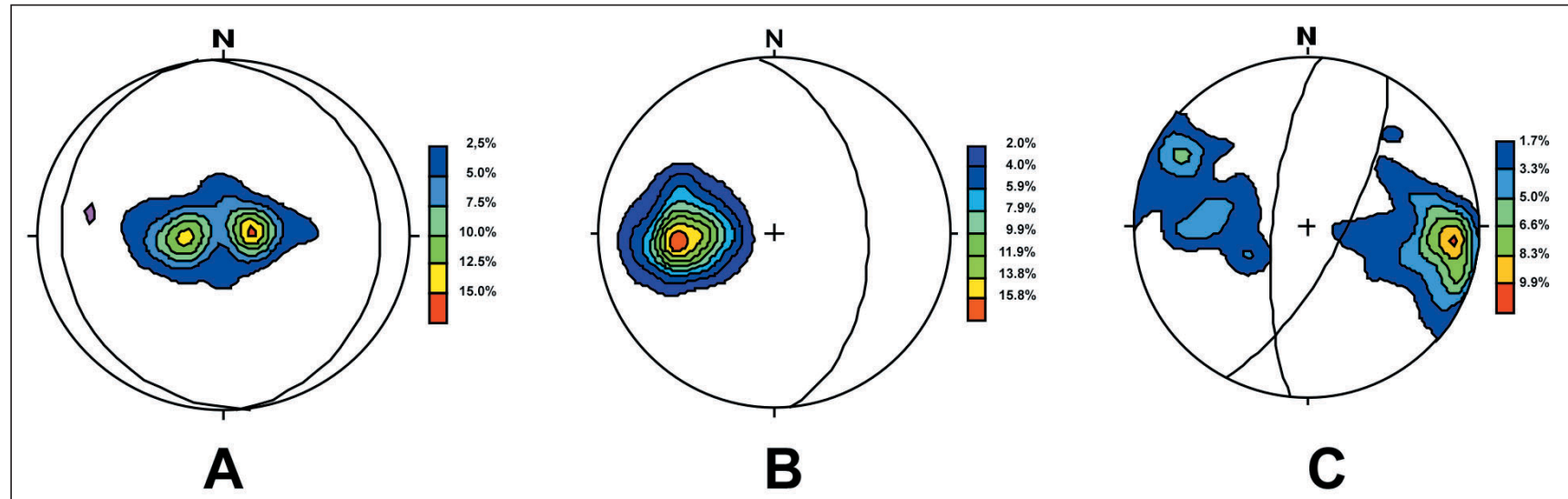

Figura 3 - Estereogramas das atitudes dos planos de acamamentos nos quartzitos (A), foliações em xistos e filitos (B) e dos veios de quartzo (C). 


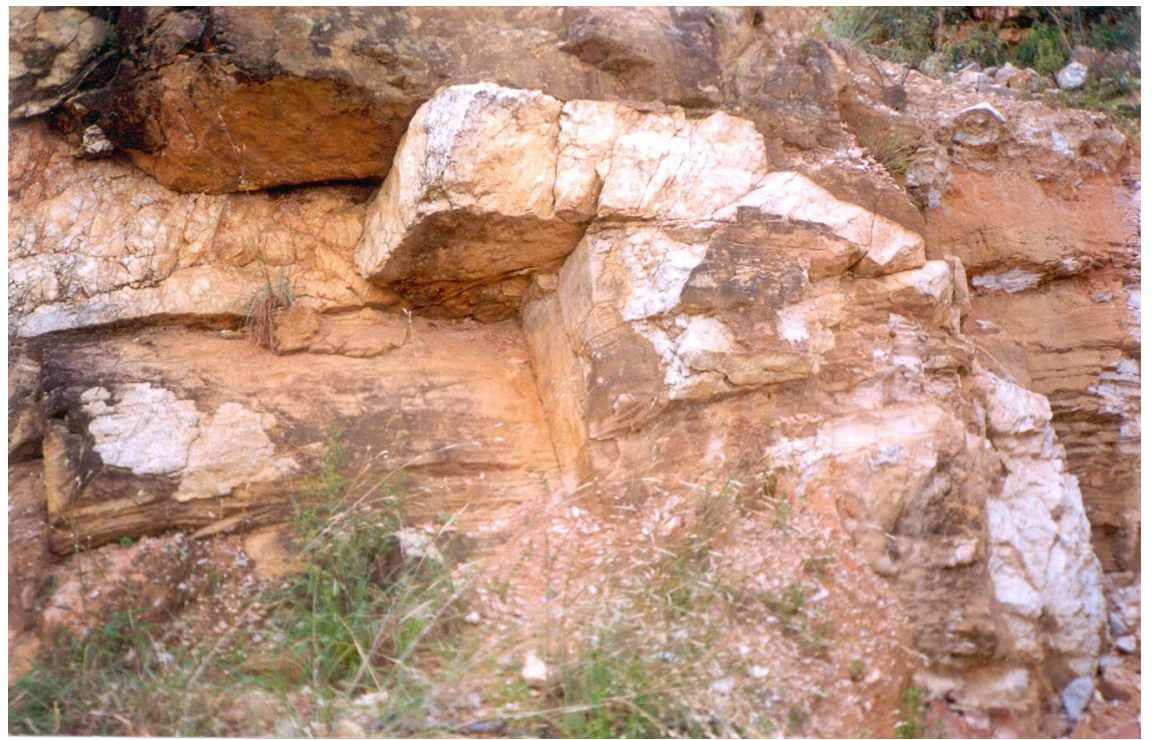

Figura 4 - Detalhe do veio de quartzo discordante (embaixo a direita da foto) passando a concordante (parte superior) à foliação e acamamento do quartzito São João da Chapada.

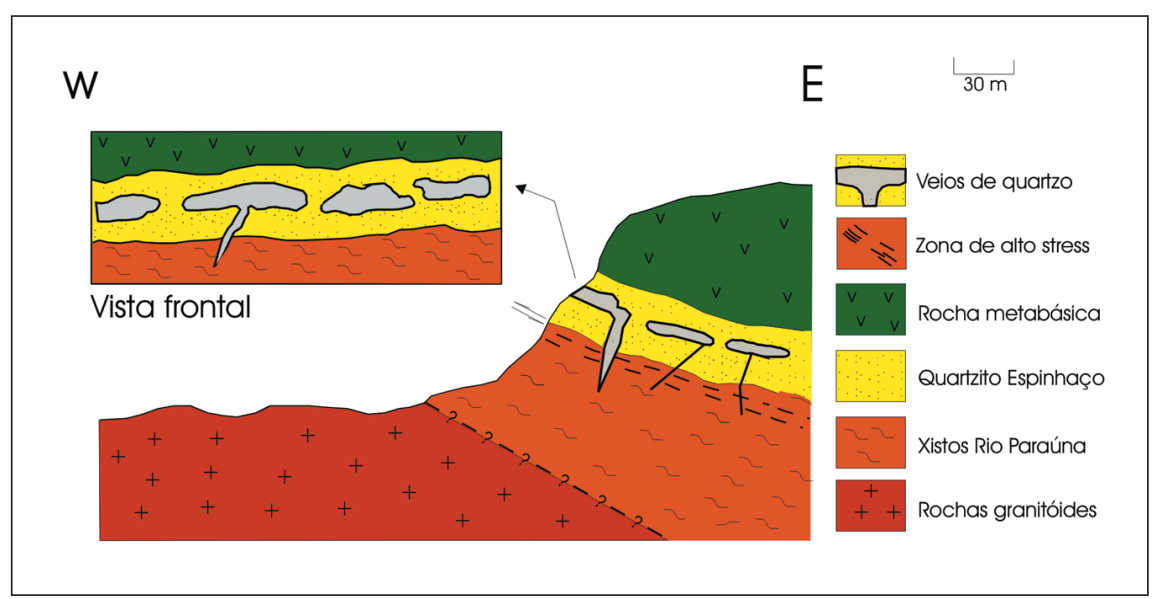

Figura 5 - Perfil geológico de detalhe a oeste da serra do Juá, mostrando o modelo esquemático de emplacement dos veios de quartzo e, na visão frontal (alto a esquerda), a morfologia geral "em rosário".

ga em zonas propícias. Em conseqüência da diminuição da temperatura nos níveis crustais superiores, a solução torna-se supersaturada depositando o quartzo onde possível. No Morro do Juá, evidenciou-se também que a presença de uma rocha altamente homogênea e impermeável (metabasito) agiu como uma barreira a essas soluções e, assim, o quartzito heterogêneo situado abaixo dela absorveu toda a mineralização. As duas direções preferenciais dos veios de quartzo, uma discordante $\left(\mathrm{N} 05^{\circ} \mathrm{E} /\right.$ $73^{\circ} \mathrm{NW}$ ) e outra concordante com a foliação local (N18 $\left.\mathrm{E} / 74^{\circ} \mathrm{SE}\right)$, indicam, respectivamente, as direções de condução e deposição dos fluidos.

A formação dos veios de quartzo na serra do Espinhaço ocorreu durante o Ciclo Brasiliano (Uhlein et al., 1986). Nesse evento, condições de temperaturas próximas de $400^{\circ} \mathrm{C}$ e pressões de $4 \mathrm{kbar}$ foram verificadas (cf. Hoffmann, 1980). Comparando-se tais dados com os representados na curva de solubilidade do quartzo em água (Fyfe et al., 1978), algumas observações podem ser destacadas. Assim, a quantidade de quartzo que vai precipitar no intervalo

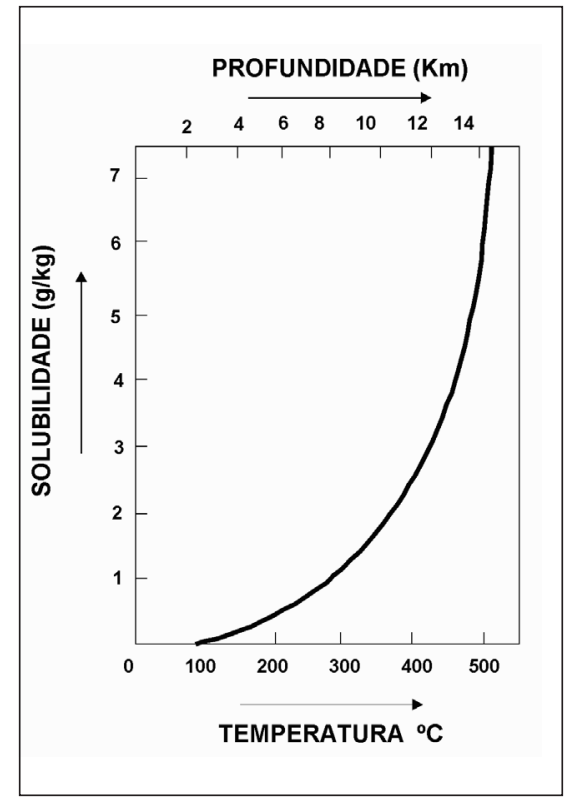

Figura 6 - Gráfico mostrando a solubilidade do quartzo em água pura com gradiente geotermobárico de $35^{\circ} \mathrm{C}$ e 300 $\mathrm{bar} / \mathrm{km}$ (segundo Fyfe et al., 1978).

de $150^{\circ}-300^{\circ} \mathrm{C}$ será igual ou inferior a $1 \mathrm{~g} / \mathrm{kg}$ de solução (Figura 6). Acima dessa faixa, o índice de solubilidade aumenta sensivelmente, até atingir o intervalo de 2-2,5 g/kg de solução, indicando que as condições de solubilidade do quartzo nessas condições de T/P são suficientemente elevadas para explicarem a grande quantidade de quartzo presente em veios na região do Espinhaço.

Fyfe et al. (1978) determinaram que a quantidade de água necessária para a precipitação de um determinado volume de quartzo é da ordem de $10^{3}$ a $10^{4}$ vezes maior do que o volume do veio. Admitindo-se, assim, que o rosário do Morro do Juá possua medidas uniformes de $2000 \mathrm{~m}$ (comprimento) x $100 \mathrm{~m}$ (largura) x $1,5 \mathrm{~m}$ (espessura), o corpo resultante seria cubado em $300.000 \mathrm{~m}^{3}$. Para tal volume de quartzo, seria, então, necessário um volume aquoso da ordem de quase $3 \times 10^{9} \mathrm{~m}^{3}$. Considerando que a maior parte do Supergrupo Espinhaço (com quase $3000 \mathrm{~m}$ de espessura na região) tenha sido originalmente formada de rochas areníticas, que são altamente porosas, é bastante plausível admitir que a água contida nessa seqüência tenha sido suficiente para suprir a geração dos veios. 


\section{Conclusão}

Controles semelhantes, definidos pela presença de uma camada "reservatório" capeada por uma camada "seladora", sob condições tectônicas de cisalhamento, parecem ser muito mais comuns do que normalmente são considerados na bibliografia. Mesmo o trabalho de maior detalhe sobre a formação dos veios de quartzo no Espinhaço (Carvalho, 1982) não deu a devida importância à camada seladora, que se tornou bastante evidente, no caso ora estudado, pela sua constituição magmática. Assim, as condições de controle observadas poderiam também ocorrer com outros litotipos e situações estruturais análogas e pesquisas nesse sentido estão sendo efetuadas em outras regiões próximas.

\section{Referências bibliográficas}

CARVALHO, A.S. Geologia e gênese das mineralizações de quartzo no Espinhaço Meridional, Minas Gerais - Brasil. Brasília:
Departamento de Geociências-UnB, 1982. 94p. (Tese de Mestrado).

CHAVES, M.L.S.C. et alii. Depósitos de quartzo da região de Batatal (Diamantina, Minas Gerais). In: SIMP. GEOL. MINAS GERAIS, 9, 1997. Ouro Preto. Anais... Ouro Preto: SBG-MG, 1997, p.103-104.

CHAVES, M.L.S.C. et alii. Tipologia dos depósitos de quartzo gemológico de Minas Gerais. In: SIMP. GEOL. MINAS GERAIS, 10, 1999. Brasília. Anais... Brasília: SBG-MG, 1999, p.42.

CRUZ, S.C.P. Zonas de cisalhamento no núcleo do Anticlinal de Gouveia (MG): processos deformacionais e metamórficos. Ouro Preto: Escola de Minas/UFOP, 2000. 276p. (Dissertação de Mestrado).

DOSSIN, T.M. et alii. Mineralizações auríferas associadas às zonas de cisalhamento brasilianas do Espinhaço Meridional (Minas Gerais). Revista de Geologia, v.3, p.19-28, 1990.

DOSSIN, T.M. Associations volcano-plutoniques de l'Espinhaço Meridional (SE-Bresil). France: Univ. d'Orléans, 1994. 177p. (Tese de Doutoramento).

FAVACHO-SILVA, M.D. Variedades gemológicas de quartzo em Minas Gerais: geologia, mineralogia, causas de cor, técnicas de tratamento e aspectos mercadológicos. Belo Horizonte: IGC/UFMG, 2000. 182p. (Dissertação de Mestrado).
FOGAÇA, A.C.C., SCHÖLL, W.U. Estratigrafia e tectônica das rochas arqueanas e proterozóicas da região de Guinda e Gouveia (MG). In: CONGR. BRAS. GEOL., 33, 1984. Rio de Janeiro. Anais... Rio de Janeiro: SBG, 1984, v.2, p.2638-2653.

FYFE, W.S. et alii. Fluids in the earth's crust. New York: Elsevier, 1978. 325p.

HOFFMANN, C. Neugliederung und geologische Geschichte der "Präminas-Gesteine" in der Südlichen Serra do Espinhaço, Minas Gerais, Brasilien. Forsch. Geol. Paläont., v.51, p.183197, 1980.

PFLUG, R. A geologia da parte meridional da serra do Espinhaço e zonas adjacentes, Minas Gerais, Brasil. Bol. Div. Geol. Mineral. v.226, p.1-55, 1965.

RAMBERG, H. Natural and experimental boudinage and pinch-and-swell structures. Jour. Geol., v. 63, p. 512-526, 1955.

ROUTHIER, P. Les Gisements Métallifères, Tome I. Paris: Masson et Cie. Ed., 1963. 867p.

UHLEIN, A. et alii. Contribuição à geologia estrutural e tectônica das rochas arqueanas e proterozóicas da serra do Espinhaço Meridional. In: CONGR. BRAS. GEOL., 34, 1986. Goiânia. Anais... Goiânia: SBG, 1986, v.3, p.1191-1199.

\section{Artigo recebido em 20/11/2002 e aprovado em 6/1/2003.}

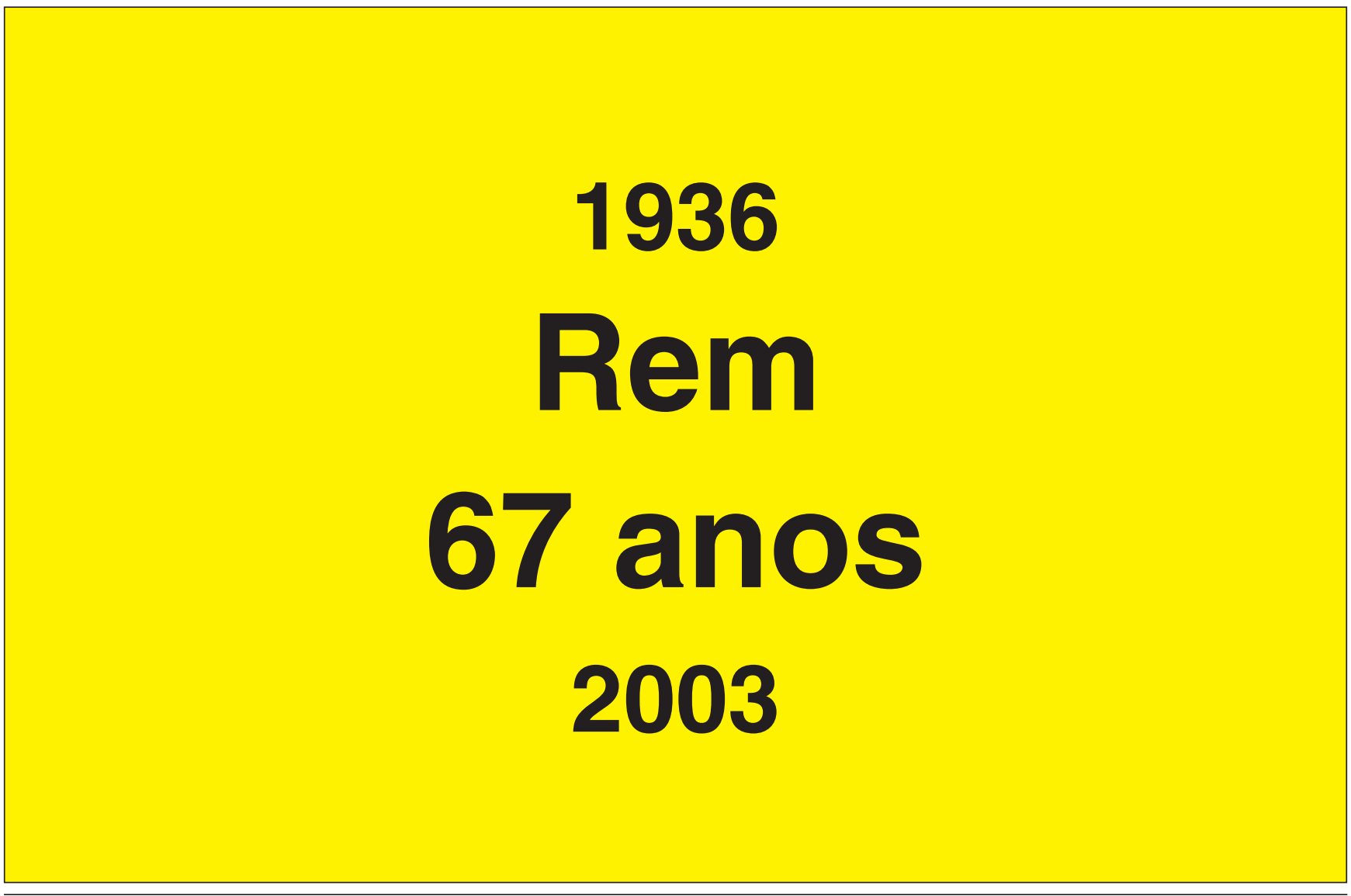

